\title{
Phosphorylation of STAT3 and ERBB2 mediates hypoxia-induced VEGF release in ARPE-19 cells
}

\author{
SOOHYUN HWANG ${ }^{1}$, HYEMIN SEONG $^{1}$, JINHYUN RYU $^{1}$, \\ JOO YEON JEONG ${ }^{1}$, TAE SEEN KANG ${ }^{2}$, KI YUP NAM ${ }^{2}$, SEONG WOOK SEO ${ }^{3,4}$, \\ SEONG JAE KIM ${ }^{3,4}$, SANG SOO KANG ${ }^{1,4}$ and YONG SEOP HAN ${ }^{2-4}$
}

\begin{abstract}
${ }^{1}$ Department of Anatomy and Convergence Medical Science, College of Medicine, Gyeongsang National University, Jinju, South Gyeongsang 52727; ${ }^{2}$ Department of Ophthalmology, Gyeongsang National University Changwon Hospital, Changwon, Gyeongsangnam-do 51472; ${ }^{3}$ Department of Ophthalmology, College of Medicine; ${ }^{4}$ Institute of Health Sciences, Gyeongsang National University, Jinju, South Gyeongsang 52727, Republic of Korea
\end{abstract}

Received September 20, 2019; Accepted June 15, 2020

DOI: $10.3892 / \mathrm{mmr} .2020 .11344$

\begin{abstract}
Neovascularization in the retina can cause loss of vision. Vascular endothelial growth factor (VEGF) serves an important role in the pathogenesis of retinal vascular diseases. Hypoxia is a notable cause of VEGF release and both STAT3 and ERBB2 are known to be associated with VEGF. In addition, STAT3 and ERBB2 interact with each other. In the present study, it was hypothesized that signal transducer and activator of transcription 3 (STAT3) and erbB-2 receptor tyrosine kinase 2 (ERBB2) may be involved in the regulation of hypoxia-induced VEGF in the retina. Cells of the retinal pigment epithelium (RPE) are an important source of VEGF. Therefore, the RPE-derived human cell line ARPE-19 was exposed to hypoxia. Hypoxia-induced phosphorylation of STAT3 and ERBB2 in ARPE-19 cells was decreased by AG490, an inhibitor of Janus kinase 2, as were hypoxia-induced VEGF release and tube formation in human umbilical vein endothelial cells. Thus, phosphorylation of ERBB2 and STAT3 regulates hypoxia-induced VEGF release in ARPE-19 cells. The results of the present study suggested that inhibition of ERBB2 and STAT3-mediated pathways under hypoxia may represent a new strategy for treating retinal vascular disease.
\end{abstract}

Correspondence to: Dr Sang Soo Kang, Department of Anatomy and Convergence Medical Science, College of Medicine, Gyeongsang National University, 15 Jinju-daero 816 Beon-gil, Jinju, South Gyeongsang 52727, Republic of Korea

E-mail: kangss@gnu.ac.kr

Dr Yong Seop Han, Department of Ophthalmology, Gyeongsang National University Changwon Hospital, 11 Samjungja-ro, Sungsan, Changwon, Gyeongsangnam-do 51472, Republic of Korea

E-mail: medcabin@naver.com

Key words: erbB-2 receptor tyrosine kinase 2, hypoxia, phophorylation, signal transducer and activator of transcription 3, vascular endothelial growth factor

\section{Introduction}

Neovascularization is associated with ocular diseases, such as age-related macular degeneration (AMD) and diabetic retinopathy (1). AMD affects the macula, leading to significant vision loss (2). Diabetic retinopathy occurs in patients with diabetes mellitus and affects the blood vessels of the retina, ultimately causing vision loss through multiple pathways (3). No surgery or drug treatment is available for patients who have already lost their vision.

A previous study have suggested that elevated levels of vascular endothelial growth factor (VEGF) serve important roles in the development of neovascularization (4). VEGF-A, the most common isoform of VEGF, is predominantly produced by cells of the retinal pigment epithelium (RPE) (5). A range of stimuli increase VEGF release from the RPE (6), including the deprivation of adequate oxygen levels, also termed hypoxia (7). Hypoxia triggers both the protein synthesis and the release of VEGF (8).

VEGF is regulated by several factors under hypoxia. Among them, signal transducer and activator of transcription 3 (STAT3) contributes to the regulation of the immune response and inflammation in RPE cells (9). Phosphorylated (p)-STAT3 translocates to the nucleus, where it activates pro-survival genes, such as survivin and Bcl-x1 (10). In addition, STAT3 activation mediates VEGF expression levels in human pancreatic cancer and retina cells $(11,12)$. Another major regulator of VEGF is erb-B-2 receptor tyrosine kinase 2 (ERBB2), a member of the epidermal growth factor family; high expression of ERBB2 contributes to tumor progression by upregulating VEGF, thus accelerating tumor vascularization $(13,14)$. STAT3 interacts with ERBB2 in breast cancer cells (15). However, the function of ERBB2 in ocular diseases remains unclear.

In the present study, a Janus kinase 2 (JAK2) inhibitor that blocks STAT3 activation (16) was used to investigate whether STAT3 and ERBB2 may regulate VEGF release in an RPE cell line. The present study also aimed to identify the proteins that regulate VEGF release in the human RPE-derived cell line ARPE-19. 


\section{Materials and methods}

Reagents. High-glucose Dulbecco's modified Eagle's medium (DMEM), high-glucose DMEM F12, penicillin, streptomycin and FBS were purchased from Gibco; Thermo Fisher Scientific, Inc. Endothelial Cell Growth Medium 2 was purchased from PromoCell GmbH. Cobalt II chloride hexahydrate $\left(\mathrm{CoCl}_{2}\right)$, JAK2 inhibitor AG490, poly-D-lysine, paraformaldehyde and DMSO were purchased from Sigma-Aldrich; Merck KGaA. Antibodies specific for hypoxia-inducible factor $1 \alpha$ (HIF-1 $\alpha)$

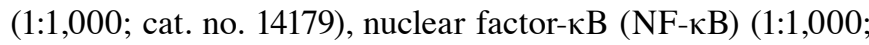
cat. no. 8242), p-NF-кB (1:1,000; cat. no. 3033), STAT3 (1:1,000; cat. no. 12640), p-STAT3 (1:2,000; cat. no. 9145), and p-ERBB2 (1:1,000; cat. no. 2243) were purchased from Cell Signaling Technology, Inc. The antibody against ERBB2 (MA5-13675; 1:1000) was purchased from Thermo Fisher Scientific, Inc. The antibody against neuregulin 1 (NRG1) (1:1,000; cat. no. ab53104) was purchased from Abcam. The antibody against lamin A/C (1:1,000; cat. no. SC-7292) was purchased from Santa Cruz Biotechnology, Inc. The antibody for $\alpha$-tubulin $(1: 5,000$; cat. no. T5168) was purchased from Thermo Fisher Scientific, Inc. The antibody against $\beta$-actin (1:10,000; cat. no. A2228) was purchased from Sigma-Aldrich, Merck KGaA. Normal donkey serum (NDS) was purchased from Bio-Rad Laboratories, Inc. Donkey anti-rabbit immunoglobulin G secondary antibody (1:200; cat. no. A-21206; Alexa Fluor $^{\circledR} 488$ conjugate) and ProLong Gold Antifade Mountant with DAPI were purchased from Thermo Fisher Scientific, Inc. BD Matrigel $^{\mathrm{TM}}$ Basement Membrane Matrix was purchased from BD Biosciences. $\mathrm{CoCl}_{2}$ was dissolved in water. AG490 was dissolved in DMSO.

Cell culture and treatment. ARPE-19 cells (American Type Culture Collection) were cultured at $37^{\circ} \mathrm{C}$ with $5 \% \mathrm{CO}_{2}$ in DMEM supplemented with $10 \% \mathrm{FBS}, 100 \mathrm{U} / \mathrm{ml}$ penicillin and $100 \mu \mathrm{g} / \mathrm{ml}$ streptomycin. For the HUVEC tube formation assay, ARPE-19 cells were cultured in DMEM F12 with 0.1\% FBS. Cells were exposed to $100 \mu \mathrm{M} \mathrm{CoCl}_{2}$ over a time course $(1,3$, $6,9,12$ and $24 \mathrm{~h}$ ) or incubated at $1 \% \mathrm{O}_{2}$ in a hypoxic incubator (MCO-5M; Sanyo). Human umbilical vein endothelial cells (HUVECs; PromoCell $\mathrm{GmbH}$ ) were seeded at a density of $1 \times 10^{5}$ cells/well in 96-well plates coated with Matrigel ${ }^{\mathrm{TM}}$ and cultured at $37^{\circ} \mathrm{C}$ with $5 \% \mathrm{CO}_{2}$ in DMEM F12 and $0.1 \%$ FBS.

Western blot. A total of $1.5 \times 10^{6}$ ARPE-19 cells were lysed in RIPA buffer (Thermo Fisher Scientific, Inc.) containing $25 \mathrm{mM}$ Tris- $\mathrm{HCl}(\mathrm{pH} \mathrm{7.6)}, 150 \mathrm{mM} \mathrm{NaCl}, 1 \% \mathrm{NP}-40$, $1 \%$ sodium deoxycholate, $0.1 \%$ SDS, protease inhibitor cocktail (Roche Diagnostics) and phosphatase inhibitor cocktail (GenDEPOT). Quantitative analysis of proteins was performed using a BCA Protein Assay kit (cat. no. 23225; Thermo Fisher Scientific, Inc). Then, a total of $30 \mu \mathrm{g}$ protein/lane was separated by SDS-PAGE on $8 \%$ gels and transferred to PVDF membranes using a Trans-Blot Turbo ${ }^{\text {TM }}$ Transfer System (Bio-Rad Laboratories, Inc.). The membranes were blocked for $2 \mathrm{~h}$ at room temperature with $5 \%$ skim milk in Tris-buffered saline containing $0.1 \%$ Tween-20 and subsequently incubated overnight with anti-HIF-1 $\alpha$, anti-p-NF- $\kappa B$, anti-NF-kB anti-p-STAT3, anti-STAT3, anti-p-HER2/ERBB2, anti-ERBB2, or anti-NRG1. Immunoreactivity was then detected using ECL reagent (Thermo Fisher Scientific, Inc.) on an Image Reader LAS 4000(Fujifilm Wako Pure Chemical Corporation).

Cytoplasmic and nuclear protein extraction. Cells were harvested and washed with cold PBS. The cell pellet was resuspended in extraction buffer A (10 mM HEPES; $1.5 \mathrm{mM} \mathrm{MgCl}_{2}$; $10 \mathrm{mM} \mathrm{KCl}$ ) containing $0.5 \mathrm{mM}$ DTT, protease inhibitors and phosphatase inhibitors. Following incubation for $20 \mathrm{~min}$ on ice, the cytoplasmic extract was separated by centrifugation at $13,475 \mathrm{x} \mathrm{g}$ for $10 \mathrm{~min}$ at $4^{\circ} \mathrm{C}$. The pellet was washed with cold PBS and resuspended in extraction buffer C (20 mM HEPES; $1.5 \mathrm{mM} \mathrm{MgCl} ; 420 \mathrm{mM} \mathrm{NaCl} ; 0.2 \mathrm{mM}$ EDTA) containing $25 \%$ glycerol, $0.5 \mathrm{mM}$ DTT, protease inhibitors and phosphatase inhibitors. After incubation for $30 \mathrm{~min}$ on ice, the nuclear extract was separated by centrifugation at $13,475 \mathrm{x} \mathrm{g}$ for $20 \mathrm{~min}$ at $4^{\circ} \mathrm{C}$. $\beta$-actin was used as a loading control. In addition, $\alpha$-tubulin was used as cytoplasmic protein marker, while lamin A/C served as nuclear protein marker. Data were analyzed by western blot.

Immunocytochemistry. ARPE-19 cells were seeded at $3 \times 10^{4}$ cells/well and incubated for $12 \mathrm{~h}$ in poly-D-lysine-coated 24-well plates for cell attachment, followed by incubation at $1 \% \mathrm{O}_{2}$ in a hypoxic incubator for $24 \mathrm{~h}$. Cells were fixed with $4 \%$ paraformaldehyde for $5 \mathrm{~min}$ at room temperature and blocked with 5\% NDS for $2 \mathrm{~h}$ in room temperature. Blocked cells were incubated with anti-p-NF-кB (1:1,600; cat. no. 3033) for overnight at $4^{\circ} \mathrm{C}$. Subsequently, cells were incubated with donkey anti-rabbit immunoglobulin G secondary antibodies (1:200; cat. no. A-21206) for $1 \mathrm{~h}$ at room temperature and then mounted with ProLong Gold Antifade Mountant with DAPI overnight at room temperature (P36931). The images of coverslips were captured using fluorescence microscopy (magnification, x200; Olympus Corporation). Data were analyzed using the Olympus Fluoview 4.2 software (Olympus Corporation).

ELISA. ARPE-19 cells were seeded in 6-well plates at $5 \times 10^{4}$ cells/well and cultured in medium supplemented with $1 \%$ FBS, $100 \mathrm{U} / \mathrm{ml}$ penicillin and $100 \mu \mathrm{g} / \mathrm{ml}$ streptomycin. VEGF levels were measured using a commercial human VEGF ELISA kit (cat. no. BMS277-2) from Invitrogen; Thermo Fisher Scientific, Inc..

HUVEC tube formation assay. HUVEC tube formation assays were carried out as previously described (17-20). ARPE-19 cells were cultured in DMEM F12 medium supplemented with $0.1 \%$ FBS, $100 \mathrm{U} / \mathrm{ml}$ penicillin and $100 \mu \mathrm{g} / \mathrm{ml}$ streptomycin at $37^{\circ} \mathrm{C}$ with $5 \% \mathrm{CO}_{2}$ in the presence of $10 \mu \mathrm{M}$ AG490 and exposed to hypoxia for $24 \mathrm{~h}$. The conditioned medium (CM) obtained from ARPE-19 cells was added to HUVECs seeded in 96-well plates coated with Matrigel ${ }^{\mathrm{TM}}$ at $1 \times 10^{5}$ cells/well. HUVECs were incubated for $48 \mathrm{~h}$ with CM. ARPE-19 cells were divided into four groups as follows: i) Normoxia CM; ii) normoxia + $10 \mu \mathrm{M}$ AG490 CM; iii) hypoxia CM; and iv) hypoxia $+10 \mu \mathrm{M}$ AG490 CM. Tube formation (indicated by branch points at which at least three tubes joined), was counted and analyzed using a U-LH100HG light microscope (magnification, x100) (Olympus Corporation) with ImageJ 1.46r software (National Institutes of Health). 


$\begin{array}{cccccccc}\text { A Time (h) } & 0 & 1 & 3 & 6 & 9 & 12 & 24 \\ \mathrm{CoCl}_{2}(100 \mu \mathrm{M}) & - & + & + & + & + & + & +\end{array}$

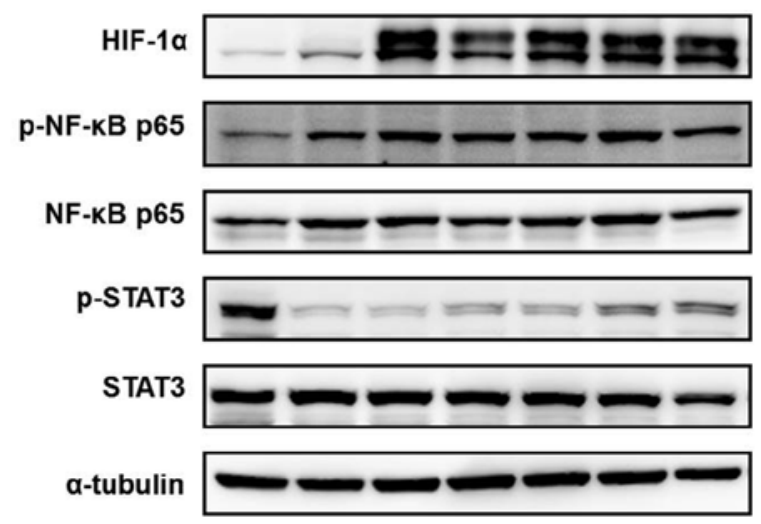

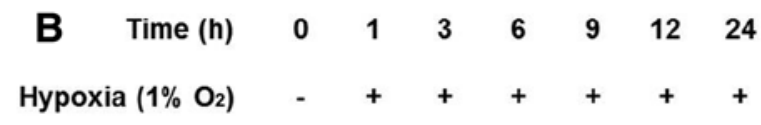

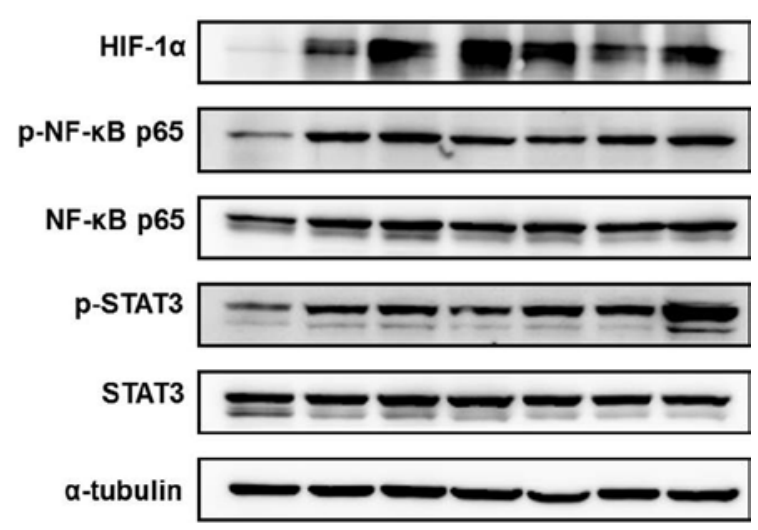

C
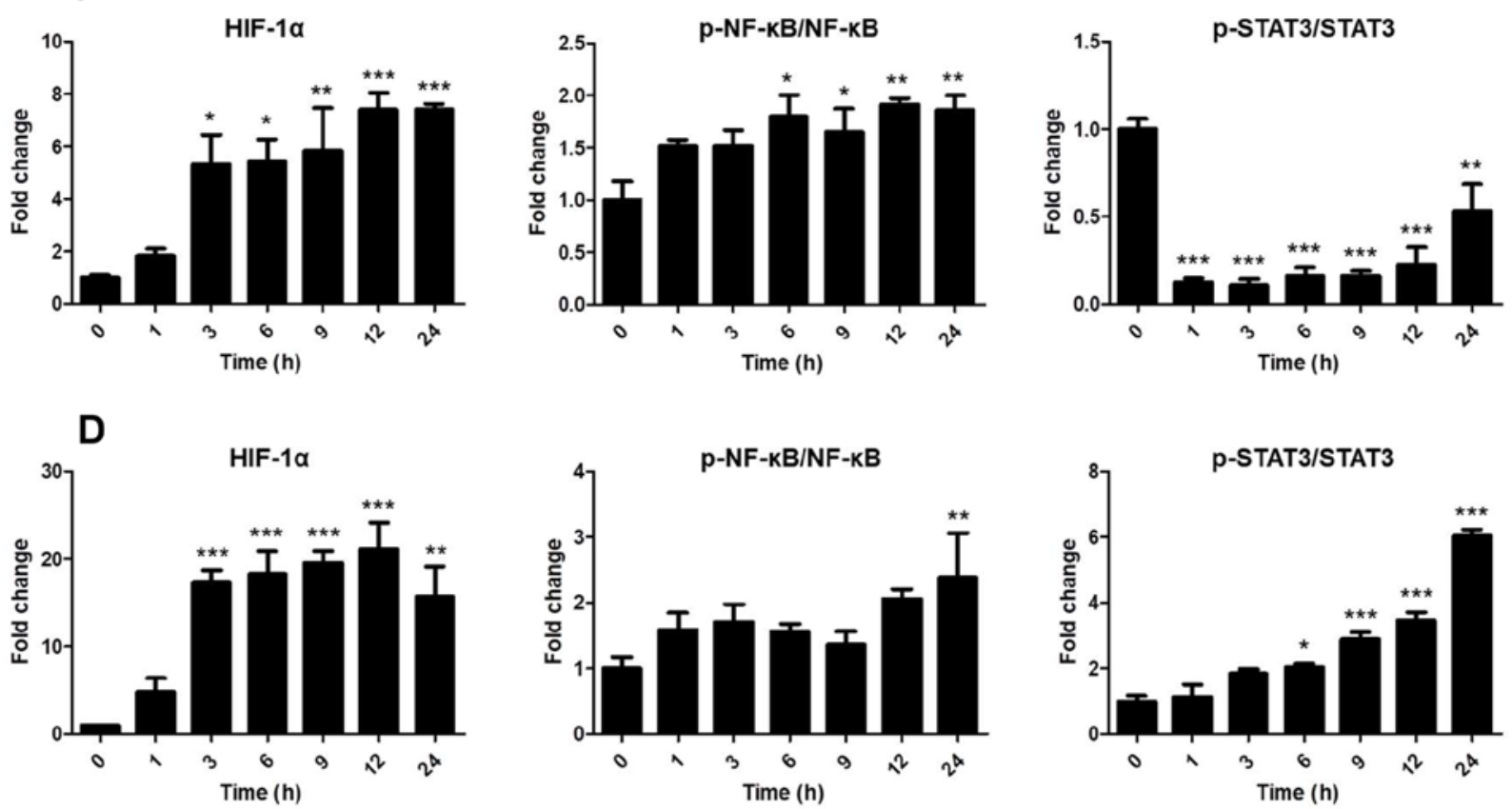

Figure 1. Hypoxic conditions affect the expression of hypoxia-associated proteins. HIF-1 $\alpha$ expression and the phosphorylation of NF- $\kappa$ B p65 and STAT3 were examined by western blotting. HIF-1 $\alpha$ expression levels and phosphorylation of NF- $\kappa \mathrm{B}$ p65 and STAT3 following (A) $100 \mu \mathrm{M} \mathrm{CoCl}{ }_{2}$ treatment and (B) hypoxic incubation $\left(1 \% \mathrm{O}_{2}\right)$ in ARPE-19 cells. (C) HIF-1 $\alpha / \alpha$-tubulin, p-p65 NF- $\mathrm{BB} / \mathrm{p} 65 \mathrm{NF}-\kappa \mathrm{B}$ and p-STAT3/STAT3 protein expression ratio following $\mathrm{CoCl}_{2}$ treatment and (D) hypoxia. Band density is expressed as fold-change relative to the control group using an arbitrary unit. Data are presented as the mean \pm SEM. ${ }^{*} \mathrm{P}<0.05,{ }^{* *} \mathrm{P}<0.01$ and ${ }^{* * *} \mathrm{P}<0.001$ vs. control $(0 \mathrm{~h})$. HIF-1 $\alpha$, hypoxia-inducible factor $1 \alpha$; STAT3, signal transducer and activator of transcription 3 ; $\mathrm{NF}-\kappa \mathrm{B}$, nuclear factor- $\kappa \mathrm{B} ; \mathrm{p}-$, phosphorylated.

Statistical analysis. All data are presented as the mean \pm SEM. Statistical analysis was performed using GraphPad Prism (version 5; GraphPad Software, Inc.). The differences between groups were analyzed using Student's t-test or one-way ANOVA followed by Dunnett's or Tukey's post hoc test. $\mathrm{P}<0.05$ was considered to indicate a statistically significant difference.

\section{Results}

Hypoxic conditions alter the expression of hypoxia-related proteins in ARPE-19 cells. Experimental hypoxia was triggered in ARPE-19 cells using treatment with $100 \mu \mathrm{M} \mathrm{CoCl}_{2}$ or a hypoxic incubator $\left(1 \% \mathrm{O}_{2}\right)$, and the levels of hypoxia-related proteins were measured by western blotting. Compared with that in the control group, the protein expression of HIF-1 $\alpha$ was significantly upregulated after $3 \mathrm{~h}$ both in the presence of $\mathrm{CoCl}_{2}$ treatment $(\mathrm{P}<0.05)$ and in hypoxic conditions $(\mathrm{P}<0.001)$ (Fig. 1). In addition, phosphorylation of NF- $\mathrm{BB}$ also increased $6 \mathrm{~h}$ after $\mathrm{CoCl}_{2}(\mathrm{P}<0.05)$ treatment and following $24-\mathrm{h}$ hypoxia $(\mathrm{P}<0.01)$.

By contrast, phosphorylation of STAT3 was decreased by $\mathrm{CoCl}_{2}$ treatment $(\mathrm{P}<0.01)$ but increased by hypoxia at the $24-\mathrm{h}$ time point compared with that in the control group $(\mathrm{P}<0.001)$. These results indicated that $\mathrm{CoCl}_{2}$ treatment could not identically replicate hypoxic conditions. Thus, subsequent experiments were carried out under hypoxic conditions using a $1 \% \mathrm{O}_{2}$ incubator.

Hypoxia induces phosphorylation of $N F-\kappa B$ and translocation of $p-N F-\kappa B$ from the cytoplasm to the nucleus. Since 
A
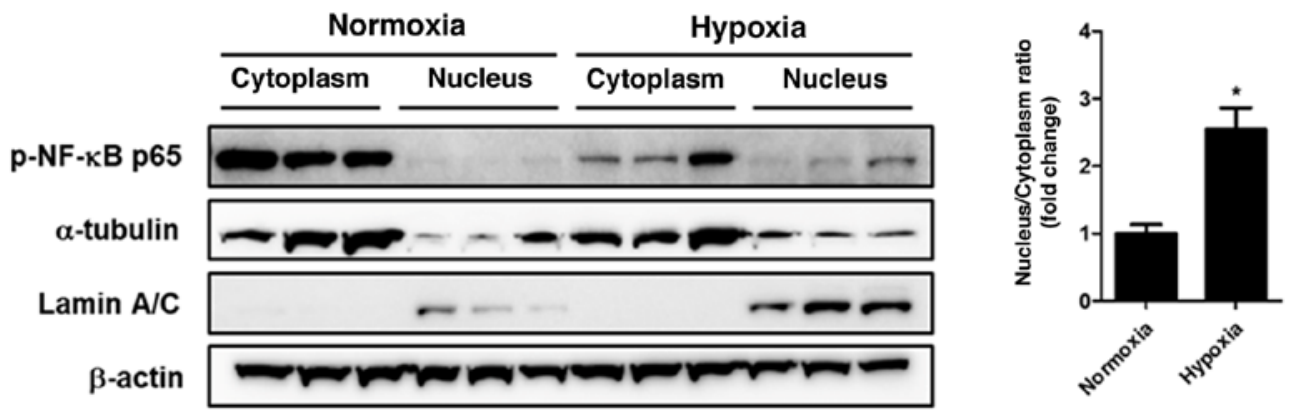

B
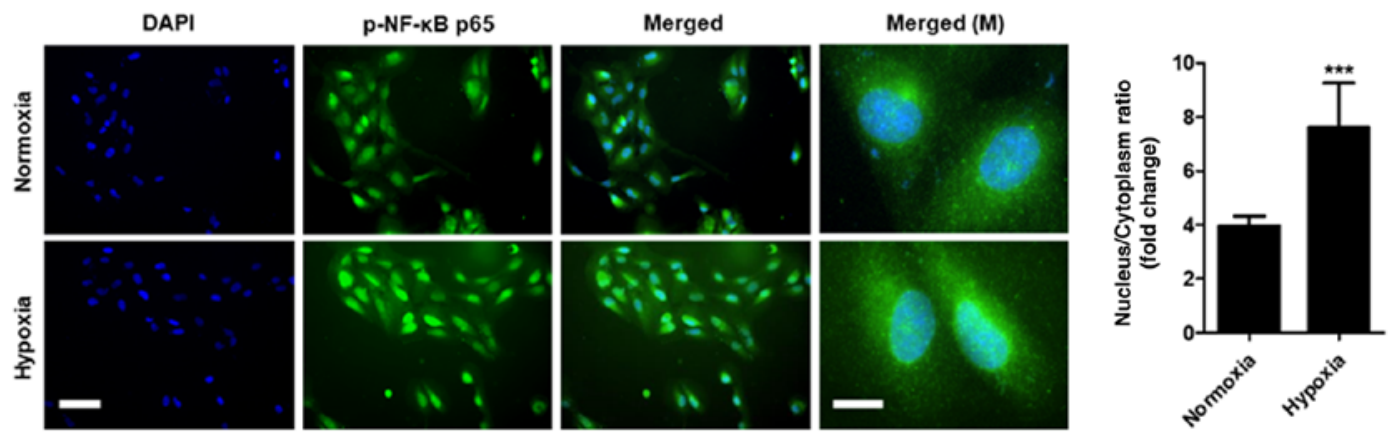

Figure 2. Hypoxia induces phosphorylation and translocation of p-NF- $\mathrm{B}$. (A) Cytoplasmic and nuclear protein expression levels following hypoxia for $24 \mathrm{~h}$ was examined by western blotting. (B) NF- $\kappa \mathrm{B}$ phosphorylation was detected by immunocytochemistry with DAPI counterstaining. Scale bar, $50 \mu$ m $(\mathrm{M}, 10 \mu \mathrm{m})$. Data are presented as the mean \pm SEM. $\mathrm{n}=3$. ${ }^{*} \mathrm{P}<0.05$ and ${ }^{* * * *} \mathrm{P}<0.001$ vs. normoxia. NF- $\kappa \mathrm{B}$, nuclear factor- $\kappa \mathrm{B}$; $\mathrm{p}-$, phosphorylated; $\mathrm{M}$, magnified.

\section{A $12 \mathrm{~h}$}

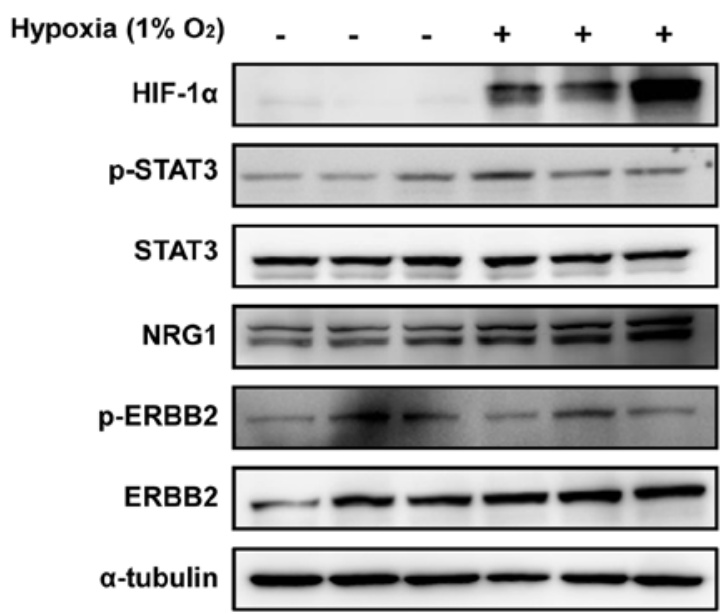

B $24 \mathrm{~h}$

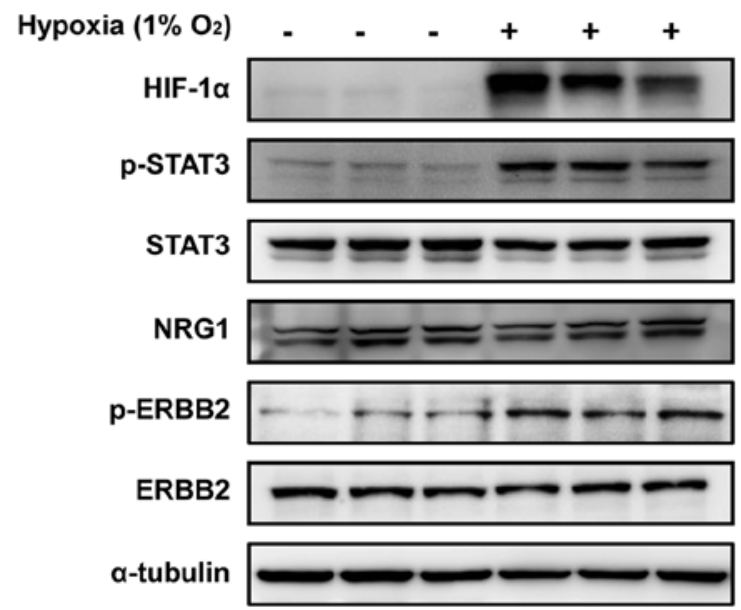

E

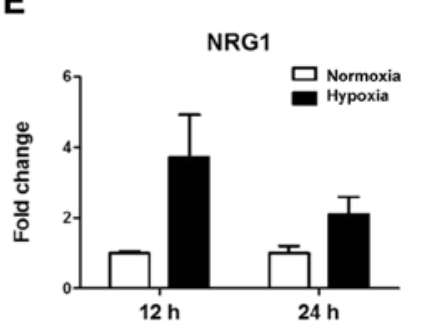

$\mathbf{F}$

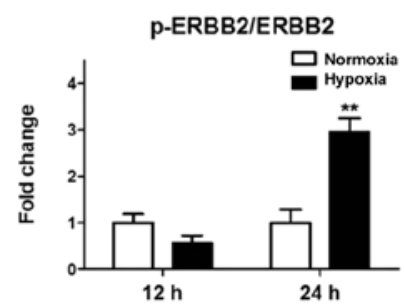

Figure 3. Hypoxia induces phosphorylation of STAT3 and ERBB2. Hypoxia-induced protein expression was examined by western blotting. (A) Hypoxia was induced in ARPE-19 cells for $12 \mathrm{~h}$. (B) Hypoxia was induced in ARPE-19 cells for $24 \mathrm{~h}$. (C) HIF-1a, (D) p-STAT3/STAT3, (E) NRG1 and (F) p-ERBB2/ERBB2 protein expression. Band density is expressed as fold-change of each group relative to the control. Data are presented as the mean $\pm \mathrm{SEM}$. ${ }^{*} \mathrm{P}<0.05$, ${ }^{* *} \mathrm{P}<0.01$ and ${ }^{* * *} \mathrm{P}<0.001$ vs. normoxia. HIF-1 $\alpha$, hypoxia-inducible factor $1 \alpha$; STAT3, signal transducer and activator of transcription 3; ERBB2, erbB-2 receptor tyrosine kinase 2; NRG1, neuregulin 1; p-, phosphorylated. 

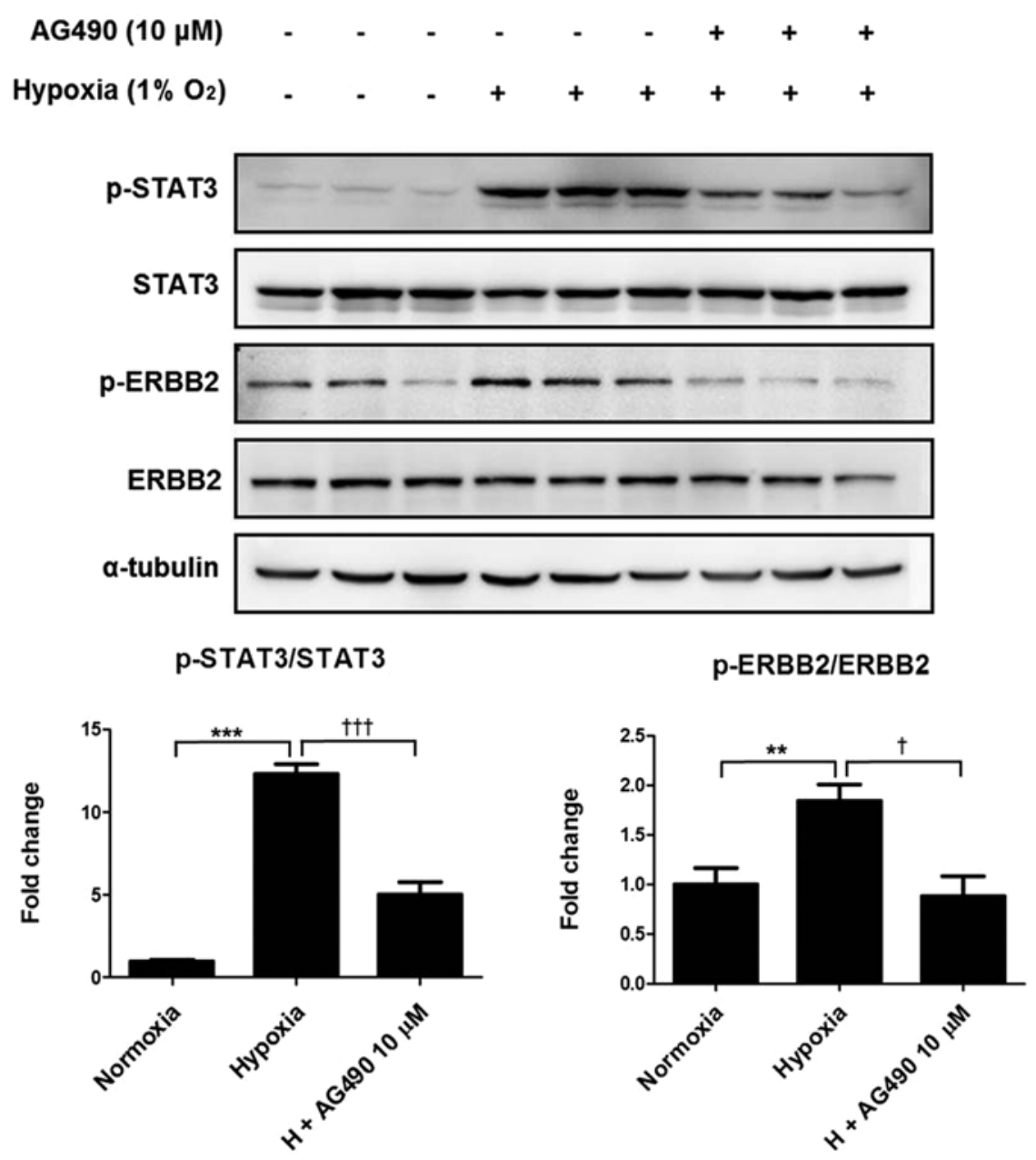

Figure 4. AG490 suppresses hypoxia-induced phosphorylation of STAT3 and ERBB2. ARPE-19 cells were exposed to hypoxia and treated with $10 \mu \mathrm{M}$ AG490 for $24 \mathrm{~h}$. Protein levels were examined by western blotting. Data are presented as the mean \pm SEM. ${ }^{* * *} \mathrm{P}<0.01$ and ${ }^{* * *} \mathrm{P}<0.001$ vs. normoxia. ${ }^{\dagger} \mathrm{P}<0.05$ and ${ }^{+} \mathrm{P}<0.001$ vs. hypoxia. STAT3, signal transducer and activator of transcription 3; ERBB2, erbB-2 receptor tyrosine kinase 2; p-, phosphorylated.

total protein analysis does not clarify the location of $\mathrm{p}-\mathrm{NF}-\kappa \mathrm{B}$, cytoplasmic and nuclear protein fractions were obtained from ARPE-19 cells. Western blot analysis of the nuclear and cytoplasmic fractions demonstrated that the levels of $\mathrm{p}-\mathrm{NF}-\kappa \mathrm{B}$ significantly increased in the nucleus following 24-h hypoxia compared with those observed under normoxia $(\mathrm{P}<0.05$; Fig. 2A). Furthermore, immunocytochemistry analysis also demonstrated the accumulation of $\mathrm{p}-\mathrm{NF}-\kappa \mathrm{B}$ in the nucleus under hypoxic conditions compared with normoxic conditions $(\mathrm{P}<0.001$; Fig. 2B). These findings demonstrated that hypoxic conditions induced the nuclear translocation of $\mathrm{p}-\mathrm{NF}-\kappa \mathrm{B}$.

Hypoxia induces the phosphorylation of STAT3 and ERBB2 in ARPE-19 cells. Phosphorylation of STAT3 and STAT3-related proteins was assessed in ARPE-19 cells incubated under hypoxic conditions for 12 (Fig. 3A) or $24 \mathrm{~h}$ (Fig. 3B). To determine whether hypoxia was induced, HIF-1 $\alpha$ was used as a hypoxic marker. Compared with that in cells under normoxic conditions, HIF-1 $\alpha$ expression increased after $12 \mathrm{~h}$ under hypoxia, and this increase was sustained at $24 \mathrm{~h}$ (Fig. 3C). Phosphorylation of STAT3 was significantly increased at the at the 24 -h time point $(\mathrm{P}<0.01)$, but not at $12 \mathrm{~h}$ (Fig. 3D) compared with that under normoxia. In addition, although NRG1 expression appeared to increase

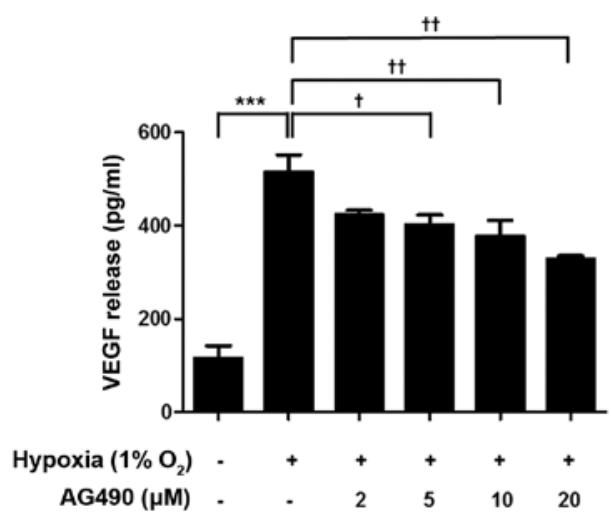

Figure 5. AG490 suppresses hypoxia-induced VEGF release. ARPE-19 cells were exposed to hypoxia and treated with the indicated concentrations of AG490 for $24 \mathrm{~h}$. VEGF release was measured by ELISA. ${ }^{* * *} \mathrm{P}<0.001$ vs. control; ${ }^{\dagger} \mathrm{P}<0.05$ and ${ }^{\dagger} \mathrm{P}<0.01$ vs. hypoxia. $\mathrm{VEGF}$, vascular endothelial growth factor.

at both time points, this effect was not significant (Fig. 3E). Phosphorylation of ERBB2 significantly increased after $24 \mathrm{~h}$ of hypoxia compared with that under normoxia (Fig. 3F). These results demonstrated that the phosphorylation of 


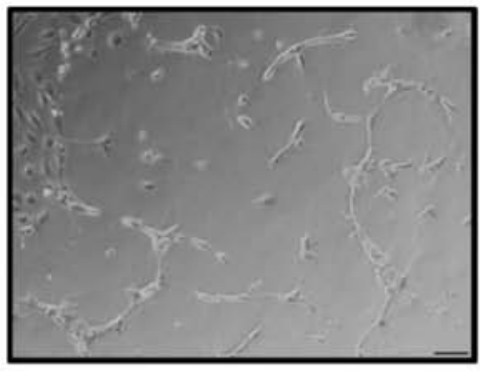

Normoxia CM

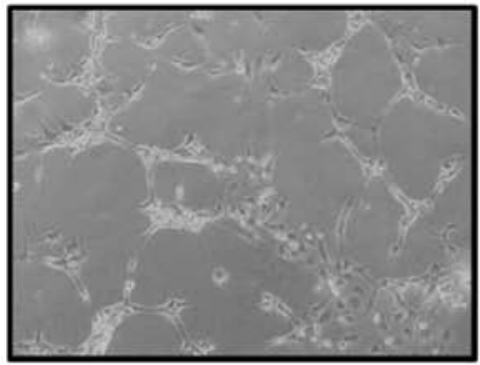

Hypoxia CM

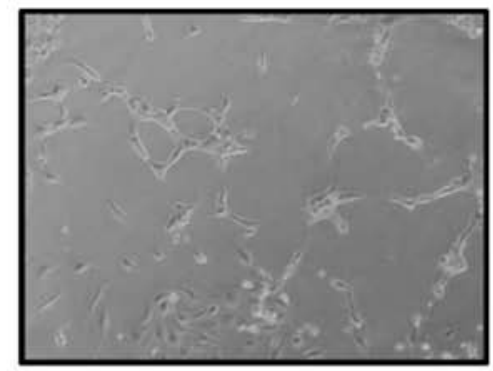

Normoxia + AG490 CM

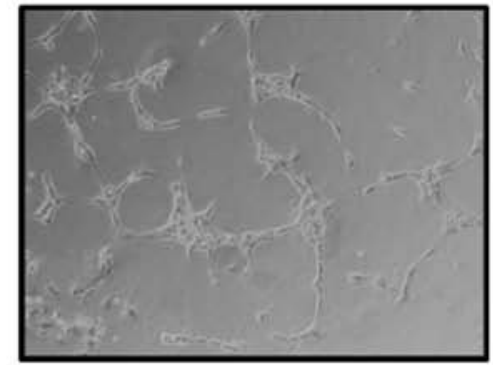

Hypoxia + AG490 CM
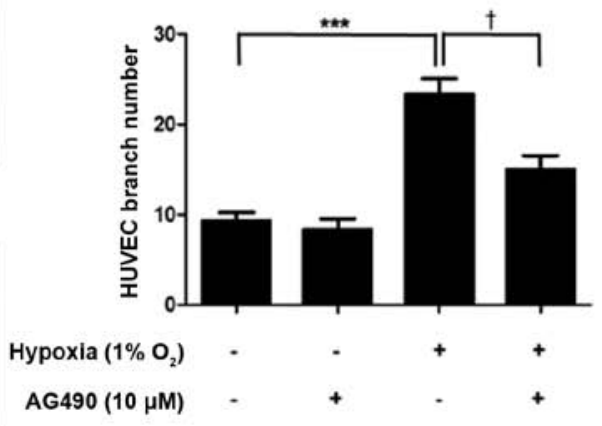

Figure 6. AG490 suppresses HUVEC tube formation. Representative images of HUVECs incubated in ARPE-19 CM under normoxia, normoxia + AG490, hypoxia and hypoxia + AG490 conditions for $48 \mathrm{~h}$ (magnification, $\mathrm{x} 100$ ). Branch numbers in HUVECs were calculated. Data are presented as the mean \pm SEM. $\mathrm{n}=3 .{ }^{* * *} \mathrm{P}<0.001$ vs. normoxia CM. ${ }^{\dagger} \mathrm{P}<0.05$ vs. hypoxia CM. HUVEC, human umbilical vein endothelial cell; $\mathrm{CM}$, conditioned medium.

STAT3 and ERBB2 increased in ARPE-19 cells following 24-h hypoxia.

AG490 suppresses hypoxia-induced phosphorylation of STAT3 and ERBB2 in ARPE-19 cells. To examine the relationship between STAT3 and ERBB2, ARPE-19 cells were treated with a commercial JAK2 inhibitor AG490 and incubated under hypoxic conditions for $24 \mathrm{~h}$. Consistent with the aforementioned results, hypoxic conditions significantly increased phosphorylation of STAT3 and ERBB2 compared with that in the control cells; however, the addition of $10 \mu \mathrm{M}$ AG490 reversed this effect, decreasing STAT3 and ERBB2 phosphorylation to levels similar to those of the control (Fig. 4). These results suggested a possible interaction between STAT3 and ERBB2, as AG490 is also a STAT3 inhibitor.

AG490 suppresses hypoxia-induced VEGF release in ARPE-19 cells. VEGF levels in ARPE-19 cells cultured under hypoxic conditions were evaluated using ELISA. Hypoxia significantly increased VEGF release in ARPE-19 cells compared with those in the control group (Fig. 5). In addition, VEGF release decreased as the dose of AG490 increased compared with untreated cells (Fig. 5). These results demonstrated STAT3 is involved in the regulation of VEGF release.

Conditioned medium (CM) from AG490-treated ARPE-19 cells suppresses HUVEC tube formation. To assess the effects of AG490 on neovascularization, a HUVEC tube formation assay was performed. After a 24-h incubation, the CM was added to HUVECs, which were incubated for an additional $48 \mathrm{~h}$.

The number of branch points significantly increased in HUVECs incubated in hypoxia CM compared with normoxia $\mathrm{CM}(\mathrm{P}<0.001)$. However, HUVECs incubated in hypoxia +
AG490 CM presented a significantly lower number of branch points compared with those incubated with hypoxia CM $(\mathrm{P}<0.05)$. The number of branch points in the normoxia + AG490 CM group was similar to the normoxia CM controls, suggesting that in AG490 alone did not affect HUVECs (Fig. 6). These findings revealed that STAT3 affects branch formation via $\mathrm{VEGF}$ release.

\section{Discussion}

Neovascularization in the retina is induced by multiple factors, and injury in newly formed blood vessels can result in visual impairment (21). Anti-VEGF therapy is widely used and highly effective for the treatment of exudative AMD and diabetic retinopathy. However, anti-VEGF agents are costly and are administered in clinic through frequent injections (22). Thus, alternative long-lasting therapeutic solutions for AMD and diabetic retinopathy are urgently required. Furthermore, a number of patients do not respond to anti-VEGF therapy or experience adverse effects, such as intraocular infection, intraocular pressure elevation, ocular hemorrhage and rhegmatogenous retinal detachment (23). Identifying and inhibiting the fundamental mechanisms of VEGF release represents a promising strategy for treating retinal vascular disease.

VEGF is regulated by HIF- $1 \alpha$ and NF- $\kappa \mathrm{B}$ p65, which are increased by hypoxia $(24,25)$. $\mathrm{NF}-\kappa \mathrm{B}$ activation is associated with phosphorylation during hypoxia $(26,27)$. The p65 subunit of $\mathrm{NF}-\kappa \mathrm{B}$ is the primary regulator of NF- $\kappa \mathrm{B}$ activity (28). In the present study, the levels of p65 phosphorylation and nuclear translocation increased under hypoxic conditions compared with those under normoxia. $\mathrm{CoCl}_{2}$ treatment inhibits degradation of HIF-1 $\alpha$ and is therefore thought to mimic hypoxia (29); in the present study, HIF-1 $\alpha$ expression and the phosphorylation 
of NF- $\kappa \mathrm{B}$ p65 were increased by $\mathrm{CoCl}_{2}$ treatment and hypoxia. However, STAT3 phosphorylation decreased following $\mathrm{CoCl}_{2}$ treatment. Although both HIF-1 $\alpha$ and STAT3 regulate VEGF expression, they have not been reported to interact with each other (30). Therefore, HIF-1 $\alpha$ was used as a marker of hypoxia in the present study. In addition, the potential interaction between ERBB2 and STAT3 was evaluated using AG490. Both ERBB2 and STAT3 were downregulated by AG490. ERBB2 overexpression induces activation of STAT3 upon tumor vascularization (31). However, to the best of our knowledge, this has not been documented in the retina. Thus, the present study aimed to determine whether STAT3 and ERBB2 could regulate VEGF release in the retina.

The RPE serves an important role in the physiology of photoreceptors, including VEGF release (32). The human ARPE-19 cell line does not develop typical epithelial cell polarization and may not be entirely representative of the retinal pigment epithelium; however, previous studies have demonstrated that APRE-19 cells display the characteristics of retinal epithelial cells $(33,34)$. In addition, ARPE-19 is a commonly used human cell line due to the difficulty in the culturing and extraction of specific RPE cells from the murine retina $(35,36)$. In the present study, phosphorylation levels of STAT3 and ERBB2 increased in ARPE-19 cells after 24 h of hypoxia. ERBB2 forms heterodimers with other ERBB receptors in a ligand-independent manner, and autophosphorylation of ERBB dimers, in turn, initiates several signaling pathways, such as RTK and MAPK pathways, which are associated with neovascularization (37-39). NRG1 is a member of the epidermal growth factor family that acts as an essential paracrine regulator of cell growth through the activation of ERBB tyrosine kinase receptors (40). Therefore, NRG1 may indirectly interact with ERBB2. However, in the present study, although NRG1 levels appeared to increase after $12 \mathrm{~h}$ of hypoxia, this effect was not significant.

AG490 is a specific inhibitor of the JAK2/STAT3 pathway $(41,42)$. In the present study, AG490 suppressed the hypoxia-induced STAT3 and ERBB2 phosphorylation in ARPE-19 cells, suggesting a potential association between STAT3 and ERBB2. However, sinceAG490 is not a specific inhibitor of STAT3, the exact upstream mediators of STAT3 and ERBB2 phosphorylation under hypoxia remain unknown. Therefore, future studies should further examine the relationship between STAT3 and ERBB2.

The RPE releases VEGF, which binds to VEGF receptors on endothelial cells, promoting new blood vessel formation (43). In the present study, AG490 suppressed hypoxia-induced VEGF release in ARPE-19 cells. In addition, the effects of VEGF secretion from RPE cells on retinal neovascularization were indirectly assessed in a HUVEC tube formation assay; HUVEC tube formation was increased by conditioned medium from ARPE-19 cells incubated under hypoxia compared with cells incubated under normoxia. However, hypoxia was inhibited in the presence of AG490. These results indicated that inhibition of STAT3 leads to a decrease in VEGF release, which decreases angiogenesis.

In conclusion, the results of the present study demonstrated that the phosphorylation of STAT3 and ERBB2 in ARPE-19 cells was increased by hypoxia, accompanied by the induction of VEGF release. AG490 suppressed these responses and ultimately decreased HUVEC tube formation. Thus, targeting the STAT3 and ERBB2 pathway represents a new strategy for alleviating neovascularization in the retina.

\section{Acknowledgements}

Not applicable.

\section{Funding}

The present study was funded by The National Research Foundation of Korea and the Ministry of Science and Information and Communications Technologies (grant no. NRF-2019R1F1A1061541) and by The Biomedical Research Institute Fund at The Gyeongsang National University Hospital (grant no. GNUHBRIF-2018-0002).

\section{Availability of data and materials}

The datasets used and/or analyzed during the present study are available from the corresponding author on reasonable request.

\section{Authors' contributions}

SH, SWS, YSH and SSK conceived the study. SH, SSK and JR developed the methodology. SH, HS, JYJ, KYN and SJK carried out the experiments. HS and TSK made contributions to the analysis and interpretation of data. $\mathrm{SH}$ wrote the initial draft of the manuscript. HS, TSK and YSH drafted and revised the manuscript critically for intellectual content. SSK, YSH and TSK reviewed and edited the manuscript. SSK and YSH supervised the study. All authors read and approved the final manuscript.

\section{Ethics approval and consent to participate}

Not applicable.

\section{Patient consent for publication}

Not applicable.

\section{Competing interests}

The authors declare that they have no competing interests.

\section{References}

1. Neely KA and Gardner TW: Ocular neovascularization: Clarifying complex interactions. Am J Pathol 153: 665-670, 1998.

2. Chappelow AV and Kaiser PK: Neovascular age-related macular degeneration. Drugs 68: 1029-1036, 2008.

3. Aiello LP, Avery RL, Arrigg PG, Keyt BA, Jampel HD, Shah ST, Pasquale LR, Thieme H, Iwamoto MA, Park JE, et al: Vascular endothelial growth factor in ocular fluid of patients with diabetic retinopathy and other retinal disorders. N Engl J Med 331: 1480-1487, 1994.

4. Kwak N, Okamoto N, Wood JM and Campochiaro PA: VEGF is major stimulator in model of choroidal neovascularization. Invest Ophthalmol Vis Sci 41: 3158-3164, 2000.

5. Klettner A, Westhues D, Lassen J, Bartsch S and Roider J: Regulation of constitutive vascular endothelial growth factor secretion in retinal pigment epithelium/choroid organ cultures: $\mathrm{p} 38$, nuclear factor $\kappa B$, and the vascular endothelial growth factor receptor-2/phosphatidylinositol 3 kinase pathway. Mol Vis 19: 281-291, 2013. 
6. Klettner A, Kaya L, Flach J, Lassen J, Treumer F and Roider J: Basal and apical regulation of VEGF-A and placenta growth factor in the RPE/choroid and primary RPE. Mol Vis 21: 736-748, 2015.

7. Shweiki D, Itin A, Soffer D and Keshet E: Vascular endothelial growth factor induced by hypoxia may mediate hypoxia-initiated angiogenesis. Nature 359: 843-845, 1992.

8. Yang X, Cao J, Du Y, Gong Q and Cheng Y: Angiopoietin-like protein 4 (ANGPTL4) induces retinal pigment epithelial barrier breakdown by activating signal transducer and activator of transcription 3 (STAT3): Evidence from ARPE-19 cells under hypoxic condition and diabetic rats. Med Sci Monit 25: 6742-6754, 2019.

9. Arjamaa O, Aaltonen V, Piippo N, Csont T, Petrovski G, Kaarniranta $\mathrm{K}$ and Kauppinen A: Hypoxia and inflammation in the release of VEGF and interleukins from human retinal pigment epithelial cells. Graefes Arch Clin Exp Ophthalmol 255: 1757-1762, 2017.

10. Patel AK, Syeda S and Hackam AS: Signal transducer and activator of transcription 3 (STAT3) signaling in retinal pigment epithelium cells. JAKSTAT 2: e25434, 2013.

11. Gutsaeva DR, Thounaojam M, Rajpurohit S, Powell FL, Martin PM, Goei S, Duncan M and Bartoli M: STAT3-mediated activation of miR-21 is involved in down-regulation of TIMP3 and neovascularization in the ischemic retina. Oncotarget 8 : 103568-103580, 2017

12. Wei D, Le X, Zheng L, Wang L, Frey JA, Gao AC, Peng Z, Huang S, Xiong HQ, Abbruzzese JL and Xie K: Stat3 activation regulates the expression of vascular endothelial growth factor and human pancreatic cancer angiogenesis and metastasis. Oncogene 22: 319-329, 2003.

13. Loureiro RM, Maharaj AS, Dankort D, Muller WJ and D'Amore PA: ErbB2 overexpression in mammary cells upregulates VEGF through the core promoter. Biochem Biophys Res Commun 326: 455-465, 2005.

14. Yang W, Klos K, Yang Y, Smith TL, Shi D and Yu D: ErbB2 overexpression correlates with increased expression of vascular endothelial growth factors A, C, and D in human breast carcinoma. Cancer 94: 2855-2861, 2002.

15. Venturutti L, Romero LV, Urtreger AJ, Chervo MF, Cordo Russo RI, Mercogliano MF, Inurrigarro G, Pereyra MG, Proietti CJ, Izzo F, et al: Stat3 regulates ErbB-2 expression and co-opts ErbB-2 nuclear function to induce miR-21 expression, PDCD4 downregulation and breast cancer metastasis. Oncogene 35: 2208-2222, 2016.

16. Li X, Cai Y, Wang YS, Shi YY, Hou W, Xu CS, Wang HY, Ye Z, Yao LB and Zhang J: Hyperglycaemia exacerbates choroidal neovascularisation in mice via the oxidative stress-induced activation of STAT3 signalling in RPE cells. PLoS One 7: e47600, 2012.

17. Maisto R, Oltra M, Vidal-Gil L, Martínez-Gil N, Sancho-Pellúz J, Filippo CD, Rossi S, D Amico M, Barcia JM and Romero FJ: ARPE-19-derived VEGF-containing exosomes promote neovascularization in HUVEC: The role of the melanocortin receptor 5 Cell Cycle 18: 413-424, 2019.

18. Chen L, Bai Y, Zhao M, and Jiang Y: TLR4 inhibitor attenuates amyloid- $\beta$-induced angiogenic and inflammatory factors in ARPE-19 cells: Implications for age-related macular degeneration. Mol Med Rep 13: 3249-56, 2016.

19. Zhao J, Geng YU, Hua H, Cun B, Chen Q, Xi X, Yang L and Li Y: Fenofibrate inhibits the expression of VEGFC and VEGFR-3 in retinal pigmental epithelial cells exposed to hypoxia. Exp Ther Med 10: 1404-1412, 2015

20. Ryu J, Seong H, Yoon NA, Seo SW, Park JW, Kang SS, Park JM and Han YS: Tristetraprolin regulates the decay of the hypoxia-induced vascular endothelial growth factor mRNA in ARPE-19 cells. Mol Med Rep 14: 5395-5400, 2016.

21. Dorrell M, Uusitalo-Jarvinen H, Aguilar E and Friedlander M: Ocular neovascularization: Basic mechanisms and therapeutic advances. Surv Ophthalmol 52 (Suppl 1): S3-S19, 2007.

22. Gacche R and Meshram R: Angiogenic factors as potential drug target: Efficacy and limitations of anti-angiogenic therapy. Biochim Biophys Acta 1846: 161-179, 2014.

23. Falavarjani KG and Nguyen Q: Adverse events and complications associated with intravitreal injection of anti-VEGF agents: A review of literature. Eye (Lond) 27: 787-794, 2013.

24. D'Ignazio L and Rocha S: Hypoxia induced NF-кB. Cells 5: 10, 2016.
25. Faridvand Y, Nozari S, Atashkhoei S, Nouri M and Jodati A Amniotic membrane extracted proteins protect H9c2 cardiomyoblasts against hypoxia-induced apoptosis by modulating oxidative stress. Biochem Biophys Res Commun 503: 1335-1341, 2018.

26. Kovacs K, Vaczy A, Fekete K, Kovari P, Atlasz T, Reglodi D, Gabriel R, Gallyas F and Sumegi B: PARP inhibitor protects against chronic hypoxia/reoxygenation-induced retinal injury by regulation of MAPKs, HIF1 $\alpha$, Nrf2, and NFкB. Invest Ophthalmol Vis Sci 60: 1478-1490, 2019.

27. Huang Z, Zheng D, Pu J, Dai J, Zhang Y, Zhang W and Wu Z: MicroRNA-125b protects liver from ischemia/reperfusion injury via inhibiting TRAF6 and NF- $\mathrm{B}$ pathway. Biosci Biotechnol Biochem 83: 829-835, 2019.

28. Albensi B: What is nuclear factor kappa $\mathrm{B}(\mathrm{NF}-\kappa \mathrm{B})$ doing in and to the mitochondrion? Front Cell Dev Biol 7: 154, 2019

29. Zhang YB, Wang X, Meister EA, Gong KR, Yan SC, Lu GW, Ji XM and Shao G: The effects of $\mathrm{CoCl} 2$ on HIF-1 $\alpha$ protein under experimental conditions of autoprogressive hypoxia using mouse models. Int J Mol Sci 15: 10999-11012, 2014

30. Gray MJ, Zhang J, Ellis LM, Semenza GL, Evans DB, Watowich SS and Gallick GE: HIF-1 $\alpha$, STAT3, CBP/p300 and Ref-1/APE are components of a transcriptional complex thatregulates Src-dependent hypoxia-induced expression of VEGF in pancreatic and prostate carcinomas. Oncogene 24: 3110-3120, 2005

31. Hawthorne VS, Huang WC, Neal CL, Tseng LM, Hung MC and Yu D: ErbB2-mediated Src and signal transducer and activator of transcription 3 activation leads to transcriptional up-regulation of p21Cip1 and chemoresistance in breast cancer cells. Mol Cancer Res 7: 592-600, 2009.

32. Ford KM, Saint-Geniez M, Walshe T, Zahr A and D'Amore PA: Expression and role of VEGF in the adult retinal pigment epithelium. Invest Ophthalmol Vis Sci 52: 9478-9487, 2011.

33. Li R, Du JH, Yao GM, Yao Y, and Zhang J: Autophagy: A new mechanism for regulating VEGF and PEDF expression in retinal pigment epithelium cells. Int J Ophthalmol 12: 557-562, 2019.

34. Li X, Zhao H, Wang Q, Liang H and Jiang X: Fucoidan protects ARPE-19 cells from oxidative stress via normalization of reactive oxygen species generation through the $\mathrm{Ca}^{2+}$-dependent ERK signaling pathway. Mol Med Rep 11: 3746-3752, 2015.

35. Giddabasappa A, Bauler MN, Barrett CM, Coss CC, Wu Z, Miller DD, Dalton JT and Eswaraka JR: GTx-822, an ER $\{$ beta\}-selective agonist, protects retinal pigment epithelium (ARPE-19) from oxidative stress by activating MAPK and PI3-K pathways. Invest Ophthalmol Vis Sci 51: 5934-5942, 2010.

36. Dunn KC, Aotaki-Keen AE, Putkey FR and Hjelmeland LM: ARPE-19, a human retinal pigment epithelial cell line with differentiated properties. Exp Eye Res 62: 155-169, 1996.

37. Olayioye MA: Intracellular signaling pathways of ErbB2/HER-2 and family members. Breast Cancer Res 3: 385-389, 2001.

38. Jeltsch M, Leppänen VM, Saharinen P and Alitalo K: Receptor tyrosine kinase-mediated angiogenesis. Cold Spring Harb Perspect Biol 5: a009183, 2013.

39. Jahejo AR, Niu S, Zhang D, Ning GB, Khan A, Mangi RA, Qadir MF, Khan A, Li JH and Tian WX: Transcriptome analysis of MAPK signaling pathway and associated genes to angiogenesis in chicken erythrocytes on response to thiram-induced tibial lesions. Res Vet Sci 127: 65-75, 2019.

40. Liang X, Ding Y, Zhang Y, Chai YH, He J, Chiu SM, Gao F, Tse HF and Lian Q: Activation of NRG1-ERBB4 signaling potentiates mesenchymal stem cell-mediated myocardial repairs following myocardial infarction. Cell Death Dis 6: e1765, 2015.

41. Selvendiran K, Bratasz A, Kuppusamy ML, Tazi MF, Rivera BK and Kuppusamy P: Hypoxia induces chemoresistance in ovarian cancer cells by activation of signal transducer and activator of transcription 3. Int J Cancer 125: 2198-2204, 2009.

42. Wang GS, Qian GS, Zhou DS and Zhao JQ: JAK-STAT signaling pathway in pulmonary arterial smooth muscle cells is activated by hypoxia. Cell Biol Int 29: 598-603, 2005.

43. Zhang H, He S, Spee C, Ishikawa K and Hinton DR: SIRT1 mediated inhibition of VEGF/VEGFR 2 signaling by Resveratrol and its relevance to choroidal neovascularization. Cytokine 76: 549-552, 2015.

This work is licensed under a Creative Commons Attribution-NonCommercial-NoDerivatives 4.0 International (CC BY-NC-ND 4.0) License. 